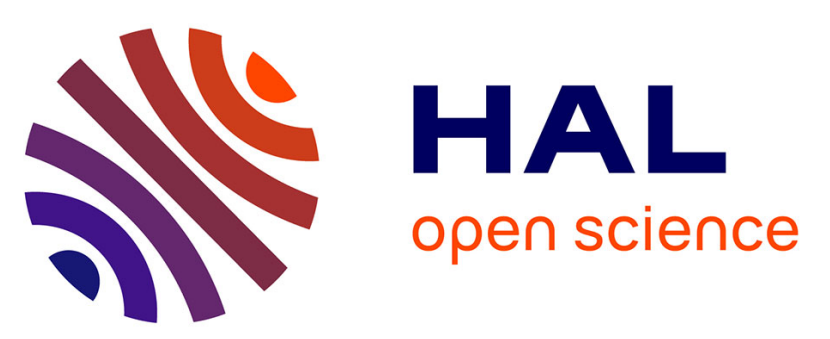

\title{
Stimulating Knowledge Search Routines and Architecture Competences: The Role of Organizational Context and Middle Management
}

\author{
Esther Tippmann, Pamela Sharkey Scott, Vincent Mangematin
}

\section{To cite this version:}

Esther Tippmann, Pamela Sharkey Scott, Vincent Mangematin. Stimulating Knowledge Search Routines and Architecture Competences: The Role of Organizational Context and Middle Management. Long Range Planning, 2014, 47 (4), pp.226-223. 10.1016/j.lrp.2013.11.001 . hal-00864332

\section{HAL Id: hal-00864332 \\ http://hal.grenoble-em.com/hal-00864332}

Submitted on 20 Sep 2013

HAL is a multi-disciplinary open access archive for the deposit and dissemination of scientific research documents, whether they are published or not. The documents may come from teaching and research institutions in France or abroad, or from public or private research centers.
L'archive ouverte pluridisciplinaire HAL, est destinée au dépôt et à la diffusion de documents scientifiques de niveau recherche, publiés ou non, émanant des établissements d'enseignement et de recherche français ou étrangers, des laboratoires publics ou privés. 
Capability evolution and a replication strategy: Stimulating middle management knowledge search routines and architecture competences

\author{
Esther Tippmann*, Dublin Institute of Technology \\ Aungier Street, Dublin 2, Ireland \\ esther.tippmann@gmail.com
}

Pamela Scott, Dublin Institute of Technology

Aungier Street, Dublin 2, Ireland pamela.sharkeyscott@dit.ie

Vincent Mangematin, Grenoble Ecole de Management

12 Rue Pierre Semard, 38000 Grenoble, France Vincent.mangematin@grenoble-em.com 


\section{Abstract}

Extending the notion of routines as stable and dynamic to the replication strategy literature, which primarily emphasises the stability and rigid execution of business templates, this qualitative study uncovers how replicating organizations can balance efforts of efficiency and standardisation and explorative knowledge search for routine modification/generation. We undertook a detailed investigation of middle managers' knowledge search routines in Gamma,a leading ICT multinational corporation, to unravel how the organizational context influences their search actions and solution development. We find that by maintaining a flexible organizational structure and not storing knowledge in central repositories - thereby foregoing the value of such mechanisms in facilitating a more efficient search and leverage of existing solutions, knowledge search routines are executed that are intense and active, break out of silos and mobilize diverse knowledge components for the architecturing of solutions. These findings contribute towards our understanding of micro-foundations of capability evolution in the context of a replication strategy by uncovering the dual workings of organizational context elements in both enabling and challenging middle managers' knowledge search actions. It also extends our understanding of the role of middle managers in capability evolution by revealing the importance of architecture competences in developing solutions that renew routines and how these competence can be stimulated by an appropriate organizational context. 


\section{Introduction}

There is a duality between routines as source of stability and change (Cohen 2007; Feldman and Pentland 2003; Turner and Rindova 2012): on the one side, routines encompass repetitive action and so denote stability, and on the other side, individual action in response to on-going change can lead to routine evolution.Although routines are simultaneously stable and dynamic, this notion is especially problematic in the context of a replication strategy. Replicating organizations 'copy' business templates, the productive, value-creating aspects of proven operational routines and capabilities, in a relatively standardised fashion for exploitation in multiple locations(Winter and Szulanski 2001; Winter et al. 2012). A key strength of the replication strategy is its focus on the processes of routine deployment, leverage and execution, emphasising routine stability and treating the underlying knowledge structure as relativelystatic or 'frozen'. The literature in this area remains relatively silent with respect to the requirement of change and renewal of the underlying routines to provide for continuous capability evolution. Winter et al. (2012: 682) acknowledge: "One must also be aware of the need to balance precise replication with adequate learning and change to remain aligned to a changing environment... the long-term success of a replicating organization is contingent on the availability of mechanisms that ensure the accurate replication of existing knowledge as well as mechanisms enabling learning and the development of new knowledge". Especially in dynamic environments, developing the organizations' capabilities is essential to respond to shifting conditions. However, with its strong effort on initial exploration to developroutines for the following exploitation, a replication strategy may drive out the creation of variation at the organizational level and so lead to longer-term organizational renewal difficulties (Felin et al. 2012; Winter and Szulanski 2001: 731).From the perspective of the organization, this poses a problematic dilemma: the organizational context facilitating the execution of a replication strategy - with 
its focus on efficiency and standardisation of 'rigid' routine functioning facilitated through a proceduralised context - can drive out explorative activities for capability evolution. The question emerges: How can organizations following a replication strategy (including a focus on standardization and efficiency) stimulate search for exploration to achieve routine modification/generation?This relates to an organizational context that allows balancing exploration and exploitation in the context of a replication strategy (March 1991).

By investigating this tension within an organization - Gamma - that was successful in stimulating knowledge search for routine modification/generation within an organizational context of operating relatively standardised business templates, the aim of this paper is to understand how the organizational context facilitated such routine modification/generation. Our focus was on investigating responses to non-routine events, critical situations of routine break-down and potential sign of the need for developing and renewing capabilities and the corresponding knowledge searches for developing adequate responses. We focused on the individual actions of middle managers, as one of the key actors in processes of bottom-up capability development(Floyd and Wooldridge 1999; King and Zeithaml 2001) and engineering organizational knowledge (Nonaka 1994), and our analysis centred on uncovering how the organizational context of Gamma influenced middle managers' knowledge searches.

We find that the lack of a central knowledge repository, which is often used to facilitate the accumulation of knowledge relating to the operation and functioning of business templates and so the access to 'ready-made' solutions, a flexible organizational design and a certain degree of knowledge modularity enable middle managers to develop search routines which combine knowledge components located within and beyond their particular functions to produce solutions that resolve the organization's current renewal problems. Rather than a 
central repository of solutions, Gamma stimulates routines for knowledge search and the exchange of knowledge components.

This paper contributes by showing how a replication strategy can accommodate the need for capability evolution. Our findings offer a more balanced view on previous arguments which emphasise that organizations operating a replication strategy should offer efficient knowledge access and reuse, as we find that the 'challenging' elements in middle managers' knowledge search routines caused by a lack of central knowledge repositories and flexible organizational structures, are in fact necessary to stimulate more active and broader interpersonal searches. Such searches serve to mobilise diverse knowledge components from within and beyond the focal function to craft new solutions. We also find that it is important for organizations wishing to introduce routine modification/generation within a replication strategy to make middle managers feel comfortable in the search for knowledge components and design of solutions - to normalise knowledge search routines alongside the efficiencydriven and relatively standardized execution of business templates.

More generally, we develop our understanding of the micro-foundations of routine and capability evolution. By combining attention to mindful action of individuals(e.g. Salvato 2009) - middle managers' search routines - with a focus on the organizational conditions one of the main micro-level components underlying the research agenda of investigating the micro-foundations of routines and capabilities (Felin et al. 2012), we were able to unravel the nature of the influence of the organizational context to achieve more complete insights on the micro-foundations of capability evolution in the context of a replication strategy.

In addition, our findings also add to the literature on the strategic role of middle managers in capability evolution. There is a danger that middle managers' role in a replication strategy becomes restricted to routine implementation and drive towards efficient execution of the 'proven' business templates, with knowledge search remaining confined to 
their immediate work context to copy general solutions. Such knowledge search that deepens their already well-developed knowledge of the routine components would compromise there critical role as engineers of knowledge and catalyst of capability evolution. We uncover the nature and functioning of knowledge architecture competences in middle managers' pursuit of explorative solution development to be able to recombine knowledge located from different sources into novel solutions, so contributing to routine modification/generation.

\section{Literature background}

\section{Capability evolution: Decentralised and mindful search routines}

Many processes of capability evolution are driven bottom-up through individual agency that triggers changes to organizational routines(Felin and Foss 2005; Felin and Hesterly 2007; Gavetti 2005), which can in turn lead to changes in organizational capabilities (Salvato and Rerup 2011). Salvato (2009) particularly highlights the role of mindful behaviourand interventions of individuals in shaping capability evolution. We follow this argument and look at search routines in response to non-routine events as a mindful accomplishment of how individuals may develop solutions that contribute to routine modification/development.

Nelson and Winter (1982) suggest that search routines can lead to changes in lowerlevel routines and are triggered by non-routine problems (Cyert and March 1963) - situations where the organization's current processes and practices offer no predetermined response. A middle manager of a sales unit, for example, may experience a sharp decline in customer retention, calling the unit's current practices into question, or (more positively), a surge in new customer demand beyond what the business's current processes can cope with. Such non-routine events offer critical learning opportunities because they are 'stop and look' moments that interrupt the predictable routines of the everyday business, reveal hidden 
weaknesses in the current routine functioning and challenge organizational members to find solutions (Felin and Foss 2009; Lampel et al. 2009).

\section{Dilemmas in knowledge search routines and the exacerbating influence of a replication} strategy

For middle managers their knowledge search routine is a way to mobilise knowledge components to generate new solutions which may modify/generate the routines underlying the capability. Although middle managers occupy a favourable position within the organization, situated at the junction of different potential search pathways that include vertical and lateral links (Mom et al. 2007; Nonaka 1994), they maytend, nevertheless, to limit their searches to a few, well-known sources (Cross and Sproull 2004; Lechner and Floyd 2007). In addition to a repetitive use of the same sources, they may search locally within the domain of their own functional backgrounds (Cyert and March 1963). By pursuing such 'narrow' knowledge searches, middle managers further advance their already well developed component knowledge, which refers to the accumulation of specialised expertise about the workings of that particular component within its focal function(Henderson and Clark 1990; Sanchez and Mahoney 1996). They also tend to try to copy existing solutions, even if these are only general recipes, to reduce the uncertainly of solution development (Spender 1989).

Besides this general danger of 'narrow' knowledge searches, there are a couple of typical organizational characteristics of a replication strategy that may trap middle managers even more in a situation where their search routines focus on deepening component knowledge and neglect needs for active and cross-functional knowledge search for designing new solutions that modify/generate routines. A central constraint is often the organization's mechanisms for replicating its capabilities to allow its practices and processes to be reused 
and leveraged across different business units and subsidiaries (Baden-Fuller and Winter 2007; Kogut and Zander 1993; Winter and Szulanski 2001). The aim is to replicate these capabilities in a relatively standardised fashion, i.e. to preserve their reliably functioning and well performing core at least initially (Szulanski and Jensen 2006, 2008). To facilitate standardization and maximise knowledge leverage, capability replication generally includes the codification of knowledge and its storage in central knowledge repositories where it is 'easily' accessible and reusable at scale(Anand et al. 1998; Hansen et al. 1999; Nielsen and Michailova 2007; Winter and Szulanski 2001). While codification leads to benefits in terms of efficiencies in knowledge reuse, it can cause rigidities if these 'proven' solutions developed in response to well-known and recurrent problems are applied to novel situations (Heimeriks et al. 2012; Schulz 1998).

The standardised way of operating also means that the routines are rather rigid, i.e. consisting of a pre-determined, fully-designed and specified sequence of actions (Felin et al. 2012). Middle managers' primary task is to ensure that these processes and practices are implemented and followed appropriately, ideally with only limited alterations. They thus tend to operate in highly proceduralisedorganizational contexts, characterised by efforts to incrementally improve the execution of predetermined sets of processes and practices to deliver against operational performance targets. Opportunities to explore alternative solutions that might deviate too much from the core of the 'proven' or 'best' practices are usually restricted. The role of middle managers thus remains limited and centres mostly around their traditional responsibility for top-down implementation (Wooldridge et al. 2008). This implementation role of middle managers is most suited to stable environmental conditions where changes are slow and relatively predictable.

This points to a dilemma to the extent that commonly-used knowledge search actions may not be conducive for the generation of solutions that modify/generate routine (see figure 
1), but follow a pattern of deepening existingcomponent knowledge. Especially if middle managers operate in the context of relatively standardised capabilities with their units concentrating only on a limited number of components, middle managers develop an everdeeper expertise of their inner workings (Henderson and Clark 1990), especially if these components are modular (Baldwin and Clark 1997: 85). This leads to an increasing specialisation of knowledge but at the expense of developing shared knowledge that spans domains (Carlile 2004; Postrel 2002) that would facilitate the search for diverse crossfunctional knowledge to aid the design of new solutions. Even if knowledge components have a certain level of modularity and can be more flexibly re-combined across functions to develop new solutions, a high level of knowledge architecture competence is required in order to be able to understand how various components interact, how overall systems function, and how to conceive ideas for new configurations(Henderson and Clark 1990; Sanchez and Mahoney 1996). And if organizations, such as the ones operating a replication strategy, are designed in a way that fosters the deepening of component knowledge, developing the architectural competences required to build successful new solutions becomes an even more substantial challenge.

\section{Insert figure 1 here}

Organizations operating a replication strategy face a challenge in that their focus on template leverage might neglect the need for routine modification/generation especially in dynamic environments to ensure organizational renewal. As changes in the environmentare experienced earlier at lower levels of organization rather than by top management, activating middle managers' capacity to contribute to capability evolution becomes critical. We argued that the organizational context of a replication strategy with its focus on efficiency and standardisation leading to an emphasis of codification and central storage of accumulated learning and knowledge, may cause managerial knowledge search routines that, rather than 
stepping up to the challenge of explorative search for solution generation, remain confined to the functional boundaries of the template operation and further deepen the knowledge of template components. The question emerges how organizations pursuing a replication strategy can stimulate search routines for exploration to achieve routine modification/generation? Answering this question will develop our understanding of the micro-foundations of capability evolution in the context of a replication strategy. Importantly, micro-foundations of capabilities are concerned with both, the individual mindful action (Salvato 2009) and with unravelling the influence of organizational design as an enabler or constrain of individual actions (Felin et al. 2012). In particular middle managers' effectiveness in making novel contributionsto the organizationare susceptible to the influence of the organizational context (e.g. Mollick 2012), making the investigation of their knowledge search routines as situated within an organizational context an important area of inquiry.

\section{The Study}

\section{Research Design and Setting}

Understanding micro-foundations of capability evolution can benefit from explorative research designs (Felin et al. 2012), such as an in-depth single case study as adopted for this study - to unpick the knowledge search actions of middle managers, how they are influenced by the organizational context, and the complex interactions between organization and middle management activities (Eisenhardt 1989; Yin 2009). Our in-depth case study setting was a multinational corporation andleading provider of information and communications technologies (ICT) and services, with an enviable record of continuously developing innovative products and novel business models, driving growth in both revenues and earnings: we anonymised its name to Gamma. We purposely chose the ICT industry; being a 
dynamic industry, we expected that non-routine problems, that interrupt the relative stability of the templates underlying a replication strategy, would occur regularly.

Gamma operates relatively standardised templates globally to achieve economies of scale and allowed it to grow quickly into a global leader. Its global operations are structured by region, and the home-region templates are replicated as closely as possible, while allowing certain adaptations in response to the particular host-country institutional environment. Gamma's business templates include automated software applications and a lot of business processes are IT-enabled. While these are attributes of many organizations operating a replication strategy, investigating Gamma revealed certain insights that alternative cases may not offer(Siggelkow 2007).

Gamma is a particularly interesting case for our purposes for a couple of reasons. Frist, knowledge sharing in the sales unit we studied was informal, and without an emphasis on a central storage repository, which was surprising for a number of reasons. Replicatingrelativelystandardisedbusiness processes which feature automated software applications suggests high economies of knowledge reuse that could be increased were a repository strategy pursued (Hansen et al. 1999). Furthermore, its size and geographic dispersion - Gamma employs over 20,000 employees in more than 50 globally scattered subsidiaries - would normally be seen as providing strong rationales for arranging access to knowledge through repositories which would offer access to accumulated learning independent of time or location(Anand et al. 1998; Nielsen and Michailova 2007; Olivera 2000). And finally, Gamma's extensive technology facilities and technology driven culture suggest that resistance towards IT infrastructures is not an issue.

\section{Data Collection}

The Gamma subsidiary from which we collected our data employs over 1,000 people and 
hosts various activities, and we were granted extensive access to a sales unit. Similar to their peers in other globally distributed sites, the middle managers in our focal unit were mainly line managers, whose core tasks were driving sales and optimising operations - aligning well with the efficiency focus of a replication strategy. Following our embedded case study design (Yin 2009), we gathered detailed data for two levels of analysis: a micro-level knowledge search actions of Gamma's middle managers to understand their knowledge search routines and outcomes achieved, as well as of the organizational context surrounding those efforts. A range of techniques were used, including interviews with middle managers and the unit's Business Director, and an extensive study of archival sources including internal reports on strategy, solution development and commentaries on the Gamma organization from external observers.

Our initial archival data analysis helped us to understand Gamma's overall strategy and the subsidiary's specific mandates, which set the broader context for middle management tasks and actions. We then organised eight semi-structured interviews (of approximately one hour, all recorded and transcribed verbatim) with middle managers in the subsidiary, which explored a total of 14 knowledge searches into different non-routine problems. As we were interested in uncovering how they responded to specific non-routine events, we asked them each to describe a concrete situation that occurred during the last twelve months, a time frame recent enough to allow for a precise recall of events, to describe how they searched for knowledge as part of their solution finding activities, and to elaborate on the outcomes of their actions and the solutions they developed. Further questions were geared towards capturing information about the organizational contextthat influenced their solution finding approaches. We sought to increase the level of accuracy in managers' different accounts by focusing on their specific actions rather than on their opinions, intentions or beliefs, triangulating this data with archival information and with information from the Business 
Director whenever possible. We then interviewed the Business Director (for over an hour) to explore Gamma's knowledge management strategy and discover how the focal unit exchanged knowledge with other parts of the organization (detailed notes were taken during this interview and transcribed shortly thereafter).

\section{Data Analysis}

We started the data analysis while the field work was still proceeding so as to being to make sense of the data we gathered, and adjust our data collection strategy to benefit from insights as they emerged (Miles and Huberman 1994). Guided by existing literature during the data analysis process and the surprising observation that Gamma neglected to codify its knowledge and store it centrally, we applied an abductive analytical approach(Locke et al. 2008), and followed Siggelkow's (2007) suggestion that preconceptions and frames of references are useful for contributing to field knowledge, while induction is necessary to notice surprising features of the case. The coding process generated data items ranging in length from a few words up to several paragraphs, and we used existing terminology and definitions to describe the codesand themes whenever possible. NVivo9 was used to manage the data analysis process in a systematic and consistent manner as well as to fragment, reassemble and recode data in order to generate findings progressively.

In analysing the data about specific middle managers' knowledge searches, we treated each non-routine problem and the corresponding knowledge search separately, creating a dataset with 14 cases. We investigated the specific activities undertaken as part of each search routine, including its intensity, the knowledge components mobilised, their functional origin, the presence of architectural knowledge and the development of outcomes, and summarised each in a table to facilitate cross-event comparison (Eisenhardt 1989)please see appendix for more detail). 
Another analysis focus was the unit's organizational design, with special interest in the elements of decentralisation and hierarchy, as indicators of managers' empowerment in terms of their authority to implement solutions; slack time as an indicator for how much time was available for knowledge search (Mintzberg 1979) and strategy for managing organizational knowledge (Hansen et al. 1999). In both instance, the analysis of the organizational design and strategy for managing knowledge, descriptive codes reflecting the language used by respondents were applied and then systematically aggregated into higherorder themes (appendix Tables A2 and A3 outline this analysis). In the analysis of the organizational context we made extensive use of archival information to corroborate the interview data. Finally we examined how the conditions at level of the organization influenced middle managers' knowledge searches (again explained in more detail in the appendix).

\section{Results}

Gamma is a market leader and a highly profitable and successful organization, largely because of its superior technologiesand effective business model. Previous observers note that the way Gamma is organised is the cornerstone of this continued success. Having explored this organization in depth from a middle management perspective, we argue that Gamma is also extremely successful in how it activates its middle managers in units that are charged primarily with the efficient execution of organizational capabilities to also search for knowledge in order to architecture new solutions in response to non-routine problems. This is an important aspect of anyorganization's ability torenew its capabilities to meet changing environments: insights emerged from our data that link their knowledge search routineswith Gamma's ability to modify existing and generate new routines. First, we present our findings for the micro-level analysis of managers' knowledge searches, followed by a 
coupledpresentation of the findings relating to the organizational context and its influence on middle managers' knowledge searches.

\section{Middle Managers’ Knowledge Search Routines}

Drawing on the stimulus-response pattern of problemistic search (Cyert and March 1963), we treated each non-routine problem as a stimulus that triggered a middle manager's response in the form of a particular knowledge search routines - the problems and mobilised knowledge components are listed in Table 1, which offers a schematic overview of the knowledge search activities. Our analysis of middle managers' activity patterns, unearthed four types of action: (1) intense and active search; (2) breaking silos: within and across functional search; (3) mobilizing diverse knowledge components; and (4) (re-)architecturing knowledge components into solutions which in turn modify or develop new routines. These common patterns are visualised in Figure 2 and explained in detail below.

\section{Insert Table 1 here}

\section{Insert Figure 2 here}

The first action was 'intense and active search'. Knowledge search can be a timeintense activity and managers easily close search early or rely on their own experience (Lechner and Floyd 2007). Knowledge search requires pro-activity to avoid this tendency. We found that the knowledge search routines of Gamma's middle managers were often active searches and targeted between two and six sources, depending on the nature of the problem and resulting need for additional knowledge. One of the managers explained how the solution idea triggered such an intense and active knowledge search: "the biggest part was searching for knowledge...Many months were really spent contacting various people and trying to get more information." Knowledge search was an integral part of the solution finding, required a considerable commitment, often on-going interactions to collaborate on solution 
development. Overall, the same manager noted how knowledge search "took quite a long time".

The second knowledge search action was 'within functional search', and it was common practice of Gamma managers to search for knowledge initially within their focal function, often approaching unit peers to obtain their advice and experience (as shown by arrow 1, Figure 2). One manager noted: "I just asked my previous manager who I know has had experience... and I know she was very logical and she handled them [similar situations] really well." (Manager 2, case 2). Managers also valued the knowledge of peers employed in similar roles in other locations and often tried to obtain a global perspective, and possibly solutions to, their non-routine problems: "For example, reaching other people... that are working in other regions, saying: 'Listen, I am coming across this issue, are you also coming across this? How are you dealing with this?'”(Manager 7, case 12). This served to deepen the functional knowledge search by exploring what knowledge other units operating the same business template in different geographic locations had to offer. One manager noted how she "collected information: Is it something that had been previously looked at?"(Manager 5, case 9) to ensure that, if a solution existed and could be located, that this knowledge was utilised.

Middle managers feel comfortable searching within their focal function, as their exchanges build on their already well developed, function-specific component knowledge and additional knowledge can be relatively easily absorbed. Most managersexchanged experience and advice with peers from their focal function throughout her knowledge search and solution development. Such searches are also relatively easy to organise, for example, via regular meetings with middle management peers from the same site or virtual meetings with peers in other locations. Mobilising functional knowledge also incorporated approaching lower-level management and front-line employees to obtain detailed knowledge.This also helped to deepen the middle managers' knowledge of the problem and its intricacies as 
experienced within the focal unit as well as unit-specific component knowledge.

The third knowledge search action related to 'breaking silos to pursue cross functional search'. Compared to within-function search to deepen component knowledge, cross functional searchis more difficult to organise, as it pushes middle managers to look beyond their developed component knowledge and its current architecture, and search for other knowledge outside the comfort zone of their function-specific knowledge (see arrow 2). Most of the cases studied (11 of 14) included cross-functional search with some managers reaching out intensely beyond functional boundaries. In the case of intense cross-functional search, middle managers were unable to retrieve knowledge relating to an existing solution from within their focal function, and so had to embark on creating a new solution by mobilising a range of different knowledge components, mostly specialist expertise and competence from colleagues in other functional areas: "talking with engineering about the types of solutions they could offer us to support this project and implement it. Because we knew pretty quickly, that in order to make that project work, to be able to launch it, we would highly depend on the other departments because we just wouldn't have the skill set to do that" (Manager 5, case 9). In addition, the same manager involved a "subject matter expert .... somebody extremely experienced in the operational part" to cover the various dimensions of knowledge needs and to mobilise diverse knowledge from outside her focal function (arrow 3). In cases of less intense cross-functional search, the manager could usually build on an existing solution and mobilised knowledge from other functions to help them modify the original solution to suit the specificities of the current organizational challenges.

The fourth action was to 'mobilize diverse knowledge components and (re-) architecture solutions'.By searching within and across spanned functions, the managers located various knowledge components. This searchwas iterative, involving repeated attempts to locate knowledge that could be meaningfully disaggregated and mobilised (see arrow 4). 
When possible, they used components of an existing practice, which were usually embedded in tools that automate and standardise, as their starting point for solution crafting. One manager recalled: "There are a lot of tools, best practices and processes that have been set up. So, we cannot use all of them, but we can learn a lot of what happened there [other unit]"(Manager 6, case 11). It then required skill and competence to mobilise these components, integrate and augment them to develop asolution, as one manager explained: "We tried to take the best of what they were doing ... but designed a smarter model of interacting with the customer." (Manager 8, case 14). Operating in a sales unit rather than in R\&D meant that knowledge search was not usually aimed at inventing new knowledge components per se, but searched for currently available, ideally modular, components that could be disaggregated, moved and reintegrated to craft a new solution (as shown by arrow 5). Only in a few cases was it necessary to involve development units to innovate new components, although their skills were sometimes sought to upgrade and adapt practice components that were embedded in tools located during search. Overall, middle managers' search routines concentrated on searching for components that could be disaggregated from their original use, mobilised and architectured into solutions. By exploring how knowledge can be integrated, Gamma's middle managers both drew on and developed their knowledge architecture competences, which in turn allowed them to design novel solutions.

When evaluating the impact of these new solutions, we found that routines were modified and created. One manager, for example, mobilized a tool from a sister unit that serves the execution of a one sales practice and then blended it with other knowledge to develop his own solution. He noted: “We don't replicate [business processes] exactly, because obviously the demands may be very different. So, we use that, I suppose, as a basic structure" (Manager 3, case 6). Routine generation occurred when the middle managers' solution pathed the way for the development and implementation of new process or practices which changed the 
make-up of Gamma's sales capability. One manager commented on the solution that "It's [business process] ... a new thing for us in Gamma to do" (Manager 6, case 11). Importantly many of these solutions were also implemented by sister units: "We now expanded it out of the pilot regions into more regions. And we have started to create specialist roles and new role career paths within Gamma to do this type of work" (Manager 8, case 14). These findings allowed us to conclude that our data represented examples of how Gamma's middle managers in operational units contributed towards capability evolution.

\section{The Influence of the Organizational Context on Middle Managers' Knowledge Search}

\section{Routines}

Importantly, Gamma's manner of organizing had many features that enabled its managers' knowledge searches by making them comfortable with exploring and finding new solutions that modified/generated routines in response to the organization's non-routine problems. It stimulated knowledge search routines that differed from what we would normally expect from an organization pursuing a replication strategy. The previous section outlined how the four knowledge search actions achieved changes of routines, and this section explains how Gamma's organizational context stimulated such searches. Paradoxically, Gamma'sorganizational context included enabling features but also features that created challenges for locating knowledge components and existing solutions efficiently, which could make knowledge searches challenging. The organizational context that influences Gamma managers' knowledge search routines consisted of the company's organizational design and its knowledge managementstrategy. We present our findings under these two headings below, paying particular attention to the interaction dynamics to unravel the nature of influence.

\section{Organizational Design}


Despite its replication strategy and operating similar practices and processes which would suggest a clearly defined organizational design, the actual organizational design remains flexile, summarised in Table 2. This enabled, but also created challenges for managers' knowledge search, outlined in Table 3 and now described in more detail.

\section{Insert Table 2 here}

\section{Insert Table 3 here}

First, Gamma's flexible organizational structure meant that managers' titles and department names, for example, only partly indicated their actual activities. Gamma displayed a style of organising our interviewees called "fairly unstructured" and even appeared "disorganised". Being less deterministic and rigid,this style gave its managers a level of exposure to people of wide expertise as it was less obvious who to approach during knowledge search. It led to managers browsing organizational knowledge in a more unstructured ways so increasing their chances of breaking out of their silos to locate diverse knowledge components from different functions.

Second, Gamma's flat organizational structure de-emphasised hierarchy, enabling its managers to drive solution finding and encouraging them to seek knowledge across different hierarchical levels for a more active within-function search: "It [hierarchy] can kill knowledge and knowledge transfer. That's why we have the situation where I can talk to somebody who is levels above me in the hierarchy, but I can share my ideas with him, and I don't feel uncomfortable. The same would be for him: he would not be ashamed to ask me for some details. "(Manager 1), so it was easy for Gamma's middle managers to bring together people to tap into their knowledge, deepening search within the sales function: "deep-dive on the German market"(Manager 3).

Third, the managers also noted that major company decisions were made in an inclusive way that involved consulting various internal stakeholders and key decision makers. 
This decision making style created a sense of ownership over the development of solutions, promoting more intense and active knowledge search routines. It also encouraged collaborative action among Gamma employees more widely, and managers were not shy to consult different experts, from sales but also from other functions, to gain advice and understanding.

Fourth, Gamma also gave its managers a high level of flexibility in terms of how they allocated their time. Finding time to work on non-routine problems could still be difficult,but they feltthe challenge was manageable: "But at least for me it is quite difficult to set time aside for it; a time that you actually spend. It's more that you try to squeeze as much as possible between what we are doing anyway. ... even though we are very busy, we always have time to think about the things and come up at least with potential solutions to improve them." (Manager 4). The managers felt Gamma made it possible for them to dedicate time to finding knowledge, provided it was spent on meaningful, goal-directed searches, which in turn encouraged them to make their searches more intensive and active: "I think Gamma is really good in enabling people to do that. When you need to get more information about a particular topic then you get enough time." (Manager 1).Another manager mentioned: "I did have that time ... My manager, he always knew that I'm actually spending most of my time searching ... We both knew that the objective was to have the best information available to make this project a success. "(Manager 5).Active knowledge search is a time-consuming activity, so this trusting company attitude allowed Gamma's managers to both increase the intensity of their searches and also broaden their scope, for example, by consulting previously unknown experts and specialist units. It also made middle managers more comfortable in dealing with the true scope of their problems (Tippmann et al. 2012), allowing them to explore new and comprehensive solutions that required 're-architecturing'.

While these organizational elements all played their part in facilitating their 
engagement in knowledge search actions, managers also found the less rigid organizational structure could complicate the locating of knowledge. For example, not always being aware of other units' exact activities caused by the flexible organizational structure could add unwanted levels of complexity: "When it comes to practice it becomes difficult to know what this person is doing. What is, for example, the focus of each site?" (Manager7).Another manager commented on her initial difficulties in locating experts: "A department that usually handles that, does not necessarily handle that within Gamma. Unless you have worked here, you wouldn't know that. I guess, with hindsight, I would have wished to have had... some kind of better hierarchical or contact information about the different departments")(Manager 5). So locating relevant and applicable knowledge can become more challenging, and maybe require repeated search efforts. As she noted: "There were times when I would have wished that I could get information quickly. Sometimes you would have spent some time talking to one person, several times, and then it turned out that this wasn't actually the right person to talk to. You should have talked to somebody else." Although this may appear to the manager as making their knowledge search routine less efficient, it had the side effect of triggering repeated efforts that widened the managers' search perimeters and made searches more active.

\section{Strategy for Managing Knowledge}

The second set of organizational conditions influencing middle managers' knowledge search was Gamma's loose and informal strategy for managing knowledge, summarised in Table 4, which again both enables and but can also act to obstruct managers' knowledge searches, as outlined in Table 5 and detailed below.

Insert Table 4 here

Insert Table 5 here 
First, apart from the broadly accessible internal websites carrying business reports relating to unit performance and customer analysis (largely used for standard updates on current performance and market trends), Gamma did not maintain a centralised knowledge repositoryto manage its internal knowledge resources, which we found particularly surprising, given its size,its global dispersion, the fact that its IT infrastructure that would permit highly effective searching for codified knowledge, and above all the replication of relatively standardised processes and practices. Previous studies found that organizations with such features typically emphasise knowledge codification and central storage (Hansen et al. 1999; Nielsen and Michailova 2007; Olivera 2000). This lack of centralised repositories meant knowledge search at Gamma remained person-centred, with knowledge - often tacit and embodied in individual employees - circulating freely and informally amongst them. It also meant that if a suitable solution existed but could not be located, the manager had an opportunity to re-architecture a solution. Although such re-architecturing might seem like 'duplication' or 'reinventing the wheel', it allowed Gamma to respond to its current renewal challenges in their present form. In certain cases, for example, it "was established, yes, it had been looked at long time ago, but a lot of those people have left since then. That knowledge would not have stayed within Gamma", with the result that it forgot some of its knowledge, giving managers the opportunity to design a new solution. If the environment is changing fast, then such re-designing of the solution allows tackling the current organizational challenge in a tailored manner, introducing fresh solutions that continuously adapt organizational routines.

Second, the open, informal way in which knowledge was shared was characteristic of Gamma - despite its size, it had endeavoured to maintain a 'small business' culture, sustained by close relationships and plenty of informal interactions between employees. Its staff could all attend its annual international conferences to meetand exchange ideas with other 
employees, offering valuable opportunities for managers to interact with their peers from other sites and to create networks and transactive memory of 'who knows what' which they could use subsequently as channels for their searches for diverse knowledge components. A manager recalled: "A lot of the internal information gathering, I got through asking somebody I knew: 'Hey, would you know who within your network would have access, or who would be the best person I could approach for getting that information?"'. Another manager explained how these contacts enabled her active search for knowledge and overcome the limitations of geographic distance: "For example, if I want to speak with someone in South America, I have already my contact there, so I either write an email or make a call and say: 'Listen, I am working on this issue, do you know if someone, or who is the person who is working on this?"', (Manager 7).It has been argued that such managerial transactive memory is important for the reconfiguration of organizational knowledge (Argote and Ren 2012). In addition, the pre-dominance of informal interpersonal interactions facilitated managers' knowledge search across functional boundaries, as one recalled: "It is an informal networking session where on a Friday afternoon, a few guys from [our function] and a few guys from [the other function] just sit together over a cup of coffee and go through: this is what we saw this week from your customers and things like that... In this informal setting, we get a lot of openness and a lot of sharing."(Manager 6). These frequent interpersonal exchanges provided both the channels and the opportunities to explore diverse knowledge components and normalised cross-functional exchanges in addition to the deepening of component knowledge which is more typical in replicating organizations.

Third, and linked to the informality of interactions, the overall company appeared relaxed and exhibited an unconstrained ethos which stimulated interactions and conveyed a sense of openness, again encouraging managers to approach peers from different functional areas seeking knowledge. Gamma managers found their colleagues willing to help and 
cooperate, and maintained their openness to sharing 'best' solutions while still being "success driven"(Director), and striving for individual achievement: "In other organizations you would have a situation where everybody says: 'Oh no, this is my product and we won't share it because we want to get all the success from it, and we want all the credit from it.' I'm happy that it doesn't work that way at Gamma ... we share knowledge and share something that works across the organization and not just hold back. "(Manager 1). This facilitated the circulation of diverse knowledge components and collaborative approaches where everybody in Gamma can contribute their knowledge.

Despite powerful rationales for repositories and codification, when it came to knowledge search Gammarelied on its managers themselves to identify and mobilise decentralised knowledge pieces embodied in peers, colleagues at other hierarchical levels or for different functional backgrounds, or incorporated in software and tools. Rather than enforcing the reuse of existing solutions, Gamma's strategy for managing knowledge stimulated search for knowledge components and solution architecture. Knowledge searching happened naturally, without relying on formal organizational guidelines or procedures: the knowledge components circulated freely among Gamma colleagues throughout the whole organization without being appropriated to a certain function. Yet, the lack of a knowledge repository which would have enabled the more efficient location of knowledge for reuse complicated managers' searches, as one manager admitted: “I just imagine if I was coming new in the company, and I worked on a project like this which happened to one of our core team members who was just recently hired. It's information overload and you really don't know where to start. Which would be the right department? Who would be the person responsible?"(Manager 5).

Despite initial frustrations among managers that the lack of central storage of knowledge inhibited a very efficient search, it was in fact these challenging elements that 
made the managers more resourceful and determined in their search: it triggered more active and repeated searches, and increased chances of locating diverse knowledge components, which promoted the free circulation of knowledge components within and across functions. The de-emphasis of knowledge repositories also meant that existing solutions were overlooked (not located during search), leading to the need to create another solution: "we don't know what the other teams are doing. So, there is a lot of duplication as a result of that" (Manager 4). Although this might seem like duplication to managers, it was effective for Gamma in that solution finding and architecturing was decentralised, and addressed the organization's current non-routine problems specifically and at their source. So, overall, Gamma's organizational conditions made its middle managers comfortable in knowledge search - leading to the emergence of knowledge search routines which supported solution architecture rather than an emphasis on the reuse of general repository-held solutions.

\section{Discussion}

In environments where change is fast-paced, organizationsfollowing a replication strategy need to find ways to balance the relative standardisation of templates to ensure organizational efficiencies in executing well-proven and scalable routines, while at the same time providing for the on-going development of the underlying knowledge structures to respond to environmental change for long-term survival(Winter et al. 2012). This poses two contradicting demands at theseorganizations. This paper explores how an organization Gamma - provides for capability evolution within the context of a replication strategy by activating middle managers' explorative knowledge search routines to develop solutions which modify/generate new routines in response to the organization's current non-routine problems. We find that Gamma's organizational context makes its middle managers comfortable in pursuing knowledge search routines that architecture solutions rather than 
promoting the efficient reuse of existing knowledge and general solutions. Gamma's middle managers are also empowered to re-design routines that have become less suited to current environmental conditions despite a focus on the relative standardised and efficient execution of business templates. These insights extend prior research on the micro-foundations of capability evolution and the strategic role of middle managers in capability development, which we will now discuss in more detail.

\section{Capability evolution in the context of a replication strategy: Institutionalising search routines alongside standardised templates}

The literature on replication strategy has tended to focus on the leverage and deployment of templates, thereby treating the underlying routine structures as relatively stable and indeed 'frozen'. Combined with an organizational context that fosters efficiency and exploitation, this creates a danger of driving out decentralised renewal activities to ensure the long-term survival. There are currently limited insights that tackle this dilemma and provide a resolution with regards to what organizational context enables middle managers to pursue the kind of explorative search routines that modify/generate routines. Unravelling how anorganizational structure - one of the main concepts in the research agenda of capability micro-foundations (Felin et al. 2012) - can enable middle managers' activities to renew routines contributes to developing our understanding of the micro-foundations of capability evolution in the context of a replication strategy.

Gamma's middle managers in the sales unit that we studied operate in a context that was primarily designed to foster the efficient reuse and execution of organizational 'best' practices. Striving for efficiency, more exploratory searches for novel solutions can become an extraordinary occurrence so that the organization is required to normalise such behaviour - that it becomes accepted as a routine rather than an exceptional response (Shepherd et al. 
2011). As our findings illustrate, many features of Gamma's organizational context, including its flexible organizational design and deformalized as well as loose strategy for managing knowledge (tables 3 and 5), facilitate knowledge search routines and solution development as they stimulate an intense and active search, help breaking silos to activate cross-functional search, and enable the mobilization of diverse knowledge components that can be architecured into novel solutions. However, the observation that Gamma de-emphasised knowledge repositories has implications for the strategic management of knowledge in organizations operating a replication strategy.

Instead of over-emphasising the reuse of 'best' solutions, middle managers in Gamma designed effective solutions that tackled specific current organizational challenges, and did so in a decentralised fashion. This was achieved by institutionalising search routines which ran alongside the company's replication strategy. Instead of finding a generic, codified solution developed in response to past challenges in a knowledge repository, middle managers developed a routine for architecturing good solutions that are closest to the market and the requirements of an evolving environment.

As the organization emphasises knowledge search routines, middle managers are free to learn from a broad spectrum of knowledge components. If an organizationstrives strongly for knowledge codification and central knowledge storage in repositories, than search may become biased towards looking for generic, ready-made solutions (Tippmann et al. 2010) and cause rigidities in routines (Heimeriks et al. 2012). Building on these insights, we find that if the organization lacks central repository storage, the 'price' to pay was more complicated searching and more challenges for managers to locate knowledge quickly (see pitfalls or challenging elements in right column of Table 5) but we also observe that the reward for Gamma was more iterative and intense searching activities of their managers and a strengthening of their competence in handling search routines.Similarly, if the organization 
has a flexible organizational structure, this again seems to complicate managers' searching (see pitfalls or challenging elements in right column of Table 3) as the location of knowledge components is harder to determine, but in fact rewards by promoting more active search routines required for explorative solution development. Our study shows that, if the organization enables knowledge search routines, middle managers develop the ability to locate and mobilise diverse knowledge components and to architecture these into novel solutions.

\section{Revealing a Strategic Competence of Middle Managers: Knowledge Search Routines for}

\section{Architecturing}

Although previous studies have pointed towards some of the required middle management competences to drive bottom-up change(Lechner and Floyd 2012; Mantere 2008; Rouleau and Balogun 2011), and noted that middle managers can be the "most direct catalyst" for exploiting key knowledge components across the wider organization(King and Zeithaml 2001: 90), little attention has yet been paid to which competences are needed to turn nonroutine problems into productive opportunities, particularly in terms of the knowledge-related abilities to mobilise components from both within and across functional boundariesto (re)architecture knowledge structures.

Our investigation reveals the importance of theorganizational context in 'pushing' middle managers to go beyond knowledge searches that are often limited, siloed and local and which may try to copy existing solutions (see Figure 1 for this conventional knowledge search pattern). Managers may feel especially uncomfortable when dealing with non-routine problems, which can be perceived as 'break-downs' or even 'failure', and their lack of confidence can further exacerbate the tendency for limited searches which appear to provide general answers for reuse, but which may only have limited applicability to their particular 
non-routine problem. In organizational terms, the difficulty is one of creeping rigidities and inertia, and a difficulty to change routines from the bottom up. But at Gamma we found middle managers were encouraged by the company's context to conduct intensive and active knowledge searches, to break out of their silos to search both within and across functions, and to mobilise diverse knowledge components which were then (re)-architectured into modified or new routines.

By exploring new solution structures of located knowledge components, middle managers at Gamma learn at the architectural level (Henderson and Clark 1990; Sanchez and Mahoney 1996). Such architectural knowledge is a prerequisite for an organization to create new knowledge, and thus represents a distinct capability (Henderson and Cockburn 1994; Kodama 2005; Kogut and Zander 1992). Developing knowledge architecture competences is particularly challenging for replicatingorganizations as knowledge specialisation biases managers towards deepening their learning about focal-function components. But middle managers need to develop competence in (re)architecturing knowledge too, if decentralised capability evolution is to be promoted: without it, they will lack sufficient ability to explore new combinations of components across functional boundaries.

\section{Implications for Management}

Despite the overall replication strategy, middle managers at Gamma are able to actively pursue actions for capability evolution. Our findings translate into five key implications for executives (summarised in Table 6) about how to create an appropriate organizational context to promote these managerial actions.

\footnotetext{
Insert Table 6 here
} 
Middle managers' activities are critical for capability evolution, and our research reveals the significance of their knowledge search routines for the organization's ability to respond to changing environments in a timely fashion.Top managers need to trust their middle managers' judgment as to when to initiate explorative solution finding processes, including if and when to replace an existing routine with re-designed processes or practices.

Encourage Knowledge Search rather than PromotingKnowledge Management Tools and

\section{Procedures}

Organizational learning experiences at Gamma were not generally codified and stored in central repositories to drive more efficient and scalable reuse of organizational knowledge rather managers used active search techniques to access knowledge components that were current and context-relevant. This suggests that promoting individuals' active knowledge seeking and developing such managerial abilities is important. Rather than structuring knowledge and its use in a central repository - and risking fossilising the templateas knowledge exchanges become static, solidifying existing routines - stimulating individual searching may be more conducive to achieving changes to routines in the face of changing environments. The knowledge managers sought was subject to constant refinement, extension and change, so creating lively knowledge that moved Gamma on from previous solutions. This interpersonal knowledge search then enabled interactive knowledge creation. Encouraging searching, rather than focussing on knowledge management tools and procedures, may be particularly useful in the managerial context, as it has been demonstrated that such tools are either not utilised effectively or are completely ignored in such timepressured work environments (Swan et al. 2010).

Utilise Advantages of Knowledge Modularity when Architecturing Solutions 
Gammaoperates in many countries and a few market segments, so its managers can use similar knowledge components from different situations - certain knowledge components exhibit degrees of modularity and, if securedduring knowledge search and utilised with the help of theirarchitectural abilities, managers can explore novel combinations of existing knowledge componentsmore flexibly.

\section{Value Individual Discovery and Re-ArchitecturingOverRigid Replication}

Our data suggests that another important feature of stimulating knowledge search routines is the value such a focus places on individual discovery over the rigid reuse of previous solutions. Codifying learning originating from one site and storing it centrally would make knowledge accessible for later and broader access, for example, when a similar non-routine problem is encountered at a sister unit. But because the choice at Gamma had been largely to eschew this mechanism, middle managers were sometimes unaware of existent routines and created new solutions, which meant (as here) that managers treated non-routine problems as knowledge generation opportunities rather than as replication exercises. This has important implications: while our results not deny the idea that the replication of routines can stimulate a new learning cycle through the adaptation of practices to a different context (Zollo and Winter 2002), our results also suggest that not providing a central repository for 'easy' replication of past solutions can stimulate the building of new routines.Our findings suggest that allowing for the occasional renewed development of solutions - instead of repeated replication - can induce fresh thinking and challenge routines which are merely satisfactory and where additional learning may have become marginal or may have stopped (Winter 2000). While the superior ability to transfer routines and capabilities internally is an advantage(Kogut and Zander 1993), our results imply that its 'non-rigid' enforcement - and the associated lower incidences of reusing existing knowledge - may stimulate the 
development of knowledge architecture competences. Codifying, documenting and storing are long and costly processes - for Gamma, exchanging partial solutions embedded in knowledge components seems to constitute an effective alternative. Our findings may suggest that architecturing new solutions is an integral part of a replication strategy to remain responsive tochanging environments. However, it is also important to be aware of the opportunity costs and resourcesinvolved in sustaining this approach, which may only create value in fast-paced competitive environments where organizational change can yield significant returns.

\section{Develop Knowledge Architecture Competences}

More generally, our findings suggest that renewal of routines is facilitated where knowledge components circulate freely across functions and where existing solutions can be modified or reinvented based on redesigning their architecture. The component knowledge can be acquired by managers; it directly buildson their well-developed, domain-specific knowledge about the functioning of their focal unit. Re-architecturing knowledge, however, needs focussed stimulation by the organizationwhich is based on organizational context. Managers may tend to reuse general solutions, but if the organization is designed in a way that stimulates knowledge search routines and component recombination, they are encouraged to search for knowledge across functions and to re-architecture them into new solutions, so adapting the organization's capabilities in a decentralised and responsive manner.

\section{Conclusion, Limitations and Future Work}

Many organizations such as franchise businesses and multinational corporations (MNCs) rely on a replication strategy to achieve growth and geographic coverage of their operations. Building on the view that organizations following a replication strategy also need to provide 
for routine modification and generation to ensure their long-term survival, this paper has looked at how organizations can unlock their middle managers' potential to renew routines through their responses to non-routine problems. By maintaining a flexible organizational structure and not storing its knowledge in central repositories - even at the risk of neglecting the value of such mechanisms in stimulating more efficient reuse of solutions - we show how an organization's context can stimulate the development of knowledge search routines and architecture competences among its middle managers to succeed in decentralised capability evolution.

Drawing on the specific case of Gamma and investigating in depth both its organizational context and many of its unit managers' responses to non-routine problems has allowed us to reveal these important insights. At the same time, this study has certain limitations, mostly linked to reporting the results of a single organization. First, the results are based on an organization operating within a dynamic industry where the pressure for capability evolution is relatively strong despite an overall strategy of template replication. Future studies could explore how organizations in less dynamic sectors balance the need for template stability with the need for capability evolution. In addition, Gamma is a multinational organization where country-specific changes may further reinforce the need for capability evolution compared to an organization pursuing a replication strategy that only operates within a single country. The architecturing of routines was facilitated by the modularity of certain knowledge components, like processes embedded in tools, a characteristic of certain organizational knowledge in Gamma which may notexist to the same extent in organizations which lack anintense focus on IT and automation. We also acknowledge that solving non-routine problems is only one important way in which middle managers can contribute to capability evolution. We find the organizational context has important influencing effects, and suggest this line of inquiry could be extended by looking at 
other organizational adaptation processes - such as initiative generation and strategy development - and at how organizations' structures and management styles can influence middle managers' behaviours and encourage their ability to develop the different competences they need to succeed in initiating changes to routines and capabilities. 


\section{References}

Anand, Vikas, Charles C. Manz, and William H. Glick 1998 'An organizational memory approach to information management'. Academy of Management Review 23/4: 796-809.

Argote, Linda, and Yuqing Ren 2012 'Transactive memory systems: A microfoundation of dynamic capabilities'. JOURNAL OF MANAGEMENT STUDIES doi: 10.1111/j.14676486.2012.01077.x/

Baldwin, Carliss Y., and Kim B. Clark 1997 'Managing in an age of modularity'. Harvard Business Review 75/5: 84-93.

Carlile, Paul R. 2004 'Transferring, translating, and transforming: An integrative framework for managing knowledge across boundaries'. Organization Science 15/5: 555-568.

Chreim, Samia, B. E. Williams, and C. R. Hinings 2007 'Interlevel influences on the reconstruction of professional role identity'. Academy of Management Journal 50/6: $1515-1539$.

Cohen, Michael D. 2007 'Reading dewey: Reflections of the study of routine'. Organization Studies 28/5: 773-786.

Cross, Rob, and Lee Sproull 2004 'More than an answer: Information relationships for actionable knowledge'. Organization Science 15/4: 446-462.

Cyert, Richard M., and James G. March 1963 Behavioral theory of the firm. Englewood Cliffs, New Jersey: Prentice Hall Inc.

Eisenhardt, Kathleen M. 1989 'Building theory from case study research'. Academy of Management Review 14/4: 532-50.

Feldman, Martha S., and Brian T. Pentland 2003 'Reconceptualizing organizational routines as a source of flexibility and change'. Administrative Science Quarterly 48/1: 94-118.

Felin, Teppo, Nicolai J. Foss, Koen H. Heimeriks, and Tammy L. Madsen 2012 'Microfoundations of routines and capabilities: Individuals, processes, and structures'. Journal of Management Studies doi:10.1111/j.1467-6486.2012.01052.x/ 
Felin, Teppo, and Nicolai J. Foss 2005 'Strategic organization: A field in search of microfoundations'. Strategic Organization 3/4: 441-455.

Felin, Teppo, and Nicolai J. Foss 2009 'Organizational routines and capabilities: Historical drift and a course-correction toward microfoundations'. Scandinavian Journal of Management 25/2: 157-167.

Felin, Teppo, and William S. Hesterly 2007 'The knowledge-based view, nested heterogeneity, and new value creation: Philosophical considerations on the locus of knowledge'. Academy of Management Review 32/1: 195-218.

Floyd, Steven W., and Bill Wooldridge 1999 'Knowledge creation and social networks in corporate entrepreneurship: The renewal of organizational capability'. Entrepreneurship: Theory \& Practice 23/3: 123-143.

Gavetti, Giovanni 2005 'Cognition and hierarchy: Rethinking the microfoundations of capabilities' development'. ORGANIZATION SCIENCE 16/6: 599-617.

Hansen, Morten T., Nitin Nohria, and Thomas Tierney 1999 'What's your strategy for managing knowledge?' Harvard Business Review 77/2: 106-116.

Heimeriks, Koen H., Mario Schijven, and Stephen Gates 2012 'Manifestations of higherorder routines: The underlying mechanisms of deliberate learning in the context of postacquisition integration '. ACADEMY OF MANAGEMENT JOURNAL 55/3: 703726.

Henderson, Rebecca, and Iain Cockburn 1994 'Measuring competence? Exploring firm effects in pharmaceutical research'. Strategic Management Journal 15/Winter special issue: $63-84$.

Henderson, Rebecca M., and Kim B. Clark 1990 'Architectural innovation: The reconfiguration of existing product technologies and the failure of established firms'. Administrative Science Quarterly 35/1: 9-30. 
King, Adelaide Wilcox, and Carl P. Zeithaml 2001 'Competencies and firm performance: Examining the causal ambiguity paradox'. Strategic Management Journal 22/1: 75-99.

Kodama, Mitsuru 2005 'Knowledge creation through networked strategic communities'. Long Range Planning 38/1: 27-49.

Kogut, Bruce, and Udo Zander 1992 'Knowledge of the firm, combinative capabilities, and the replication of technology'. Organization Science 3/3: 383-397.

Kogut, Bruce, and Udo Zander 1993 'Knowledge of the firm and the evolutionary theory of the multinational corporation'. Journal of International Business Studies 24/4: 625-645.

Lampel, Joseph, Jamal Shamsie, and Zur Shapira 2009 'Experiencing the improbable: Rare events and organizational learning'. Organization Science 20/5: 835-845.

Lechner, Christoph, and Steven W. Floyd 2007 'Searching, processing, codifying and practicing: Key learning activities in exploratory initiatives'. Long Range Planning 40/1: 9-29.

Lechner, Christoph, and Steven W. Floyd 2012 'Group influence activities and the performance of strategic initiatives'. STRATEGIC MANAGEMENT JOURNAL 33/5: $478-495$.

Locke, Karen, Karen Golden-Biddle, and Martha S. Feldman 2008 'Perspective-making doubt generative: Rethinking the role of doubt in the research process'. ORGANIZATION SCIENCE 19/6: 907-918.

Mantere, Saku 2008 'Role expectations and middle manager strategic agency'. Journal of Management Studies 45/2: 294-316.

March, James G. 1991 'Exploration and exploitation in organizational learning'. Organization Science 2/1: 71-87.

Miles, Matthew B., and Michael A. Huberman 1994 Qualitative data analysis: An expanded sourcebook. London: Sage. 
Mintzberg, Henry 1979 The structuring of organizations. Englewood Cliffs, NJ: PrenticeHall.

Mollick, Ethan 2012 'People and process, suits and innovators: The role of individuals in firm performance'. STRATEGIC MANAGEMENT JOURNAL 33/9: 1001-1015.

Mom, Tom J. M., Frans A. J. Van Den Bosch, and Henk W. Volberda 2007 'Investigating managers' exploration and exploitation activities: The influence of top-down, bottomup, and horizontal knowledge inflows'. Journal of Management Studies 44/6: 910-931.

Nelson, Richard R., and Sidney G. Winter 1982 An evolutionary theory of economic change. London: The Belknap Press of Harvard University Press.

Nielsen, Bo Bernhard, and Snejina Michailova 2007 'Knowledge management systems in multinational corporations: Typology and transitional dynamics'. Long Range Planning 40/3: 314-340.

Nonaka, Ikujiro 1994 'A dynamic theory of organizational knowledge creation'. Organization Science 5/1: 14-37.

Olivera, Fernando 2000 'Memory systems in organizations: An empirical investigation of mechanisms for knowledge collection, storage and access'. Journal of Management Studies 37/6: 811-832.

Polanyi, Michael 1966 The tacit dimension. Garden City, New York: Doubleday and Co.

Postrel, Steven 2002 'Islands of shared knowledge: Specialization and mutual understanding in problem-solving teams'. Organization Science 13/3: 303-320.

Rouleau, Linda, and Julia Balogun 2011 'Middle managers, strategic sensemaking and discursive competence'. Journal of Management Studies 48/5: 953-983.

Salvato, Carlo 2009 'Capabiliities unveiled: The role of ordinary activities in the evolution of product development processes'. ORGANIZATION SCIENCE 20/2: 384-409. 
Salvato, Carlo, and Claus Rerup 2011 'Beyond collective entities: Multilevel research on organizational routines and capabilities'. JOURNAL OF MANAGEMENT 37/2: 468490.

Sanchez, Ron, and Joseph T. Mahoney 1996 'Modularity, flexibility, and knowledge management inn product and organization design'. STRATEGIC MANAGEMENT JOURNAL 17/Winter Special Issue: 63-76.

Schulz, Martin 1998 'Limits to bureaucratic growth: The density dependence of organizational rule births'. ADMINISTRATIVE SCIENCE QUARTERLY 43/4: 845-876.

Shepherd, Dean A., Holger Patzelt, and Marcus Wolfe 2011 'Moving forward from project failure: Negative emotions, affective commitment, and learning from the experience'. Academy of Management Journal 54/6: 1229-1259.

Siggelkow, Nicolaj 2007 'Persuasion with case studies'. Academy of Management Journal 50/1: 20-4.

Spender, J. C. 1989 Industry recipes: An enquiry into the nature and sources of managerial judgement. Oxford: Blackwell.

Swan, Jacky, Harry Scarbrough, and Sue Newell 2010 'Why don't (or do) organizations learn from projects?' Management Learning 41/3: 325-44.

Szulanski, Gabriel, and Robert J. Jensen 2006 'Presumptive adaptation and the effectiveness of knowledge transfer'. Strategic Management Journal 27/10: 937-957.

Szulanski, Gabriel, and Robert J. Jensen 2008 'Growing through copying: The negative consequences of innovation on franchise network growth'. Research Policy 37/10: $1732-1741$.

Tippmann, Esther, Pamela Sharkey-Scott, and Vincent Mangematin 2010 'Middle managers' searching for knowledge: Repository or interpersonal dilemma'. Presented at Academy of Management Annual Meeting, Montreal, Canada. 
Tippmann, Esther, Pamela Sharkey Scott, and Vincent Mangematin 2012 'Problem solving in mncs: How local and global solutions are (and are not) created'. Journal of International Business Studies 43/8: 746-771.

Turner, Scott F., and Violina Rindova 2012 'A balancing act: How organizations pursue consistency in routine functioning in the face of ongoing change'. Organization Science 23/1: 24-46.

Winter, Sidney G. 2000 'The satisficing principle in capability learning'. Strategic Management Journal 21/10/11: 981-996.

Winter, Sidney G., and Gabriel Szulanski 2001 'Replication as strategy'. Organization Science 12/6: 730-743.

Winter, Sidney G., Gabriel Szulanski, Dimo Ringov, and Robert J. Jensen 2012 'Reproducing knowledge: Inaccurate replication and failure in franchise organizations'. ORGANIZATION SCIENCE 23/3: 672-685.

Wooldridge, Bill, Torsten Schmid, and Steven W. Floyd 2008 'The middle management perspective on strategy process: Contributions, synthesis, and future research'. Journal of Management 34/6: 1190-1221.

Yin, Robert K. 2009 Case study research: Design and methods. Thousand Oaks, CA: Sage Publications, Inc.

Zollo, Maurizio, and Sidney G. Winter 2002 'Deliberate learning and the evolution of dynamic capabilities'. Organization Science 13/3: 339-351. 


\section{Appendix A: Additional Details on Method}

\section{Data analysis: Coding procedure for middle manager's knowledge search routines}

For each knowledge source targeted by Gamma managers, we first coded the knowledge component that was exchanged, starting with the literature-based themes of tacit and codified knowledge (Polanyi 1966), gradually grouping the different knowledge components into the following categories:

- Codified:

- Practice: Process embedded in document

- Practice: Process embedded in tools

- Tacit:

- Practice: understanding of practice

- Specialist expertise, competence

- Experience, advice from peers

We then investigated the functional domain of each knowledge component, coding whether the knowledge was mobilised from within or beyond the focal function (here, within or outside sales function). Finally, the data was examined for the presence of architectural knowledge - examining whether knowledge components, originating from different functions, were combined to shape a modified or new solution. If a middle manager, for example, located knowledge in the engineering department and then worked with engineers to obtain their specialist expertise in developing a solution for the sales unit, knowledge components were combined across functions, suggesting the presence of architectural knowledge among the Gamma managers concerned. 


\section{Data analysis: Coding procedure for organizational context}

Table A1 describes Gamma's organizational context in terms of the inductively generated structure of categories.

\section{Insert Table A1 here}

\section{Data analysis: Coding procedure for influence of organization on middle managers' knowledge search}

To analyse how the organization's macro-level structure influenced its middle managers' knowledge searches at the micro-level, we followed a similar coding approach to that used by Chreim et al. (2007) to analyse inter-level effects. Initially, we identified all the explicit links between the two levels. Some respondents, for example, noted that Gamma was not prescriptive as to how managers should use their time, and that a lot of it was devoted to searching for knowledge, from which we inferred a link between the organizational element,flexible time allocation and the micro-level element,knowledge search intensity. We then compared themes arising from the micro-level data and that from the organizational context. For instance, we gained a detailed understanding of Gamma's organizational design from the interview with the Business Director and from archival sources, so when the managers referred to organizational design aspects in describing their knowledge search processes, we could triangulate these elements and note how it had influenced their knowledge searches. Memos were used extensively at this stage to increase the level of abstraction and delineate the most pertinent relationships within the data(Miles and Huberman 1994).

We employed several measures to increase the trustworthiness of our the data and our analysis, including investigating 14 responses to non-routine problems to achieve replication (Eisenhardt 1989), moving constantly between theory and data, including multiple iterations of data analysis, triangulation, protecting the confidentiality of responses, and confirming the 
validity of the initial case analysis with Gamma managers, including their feedback in the next analysis steps. 
Figure 1: Conventional model of middle managers' knowledge search

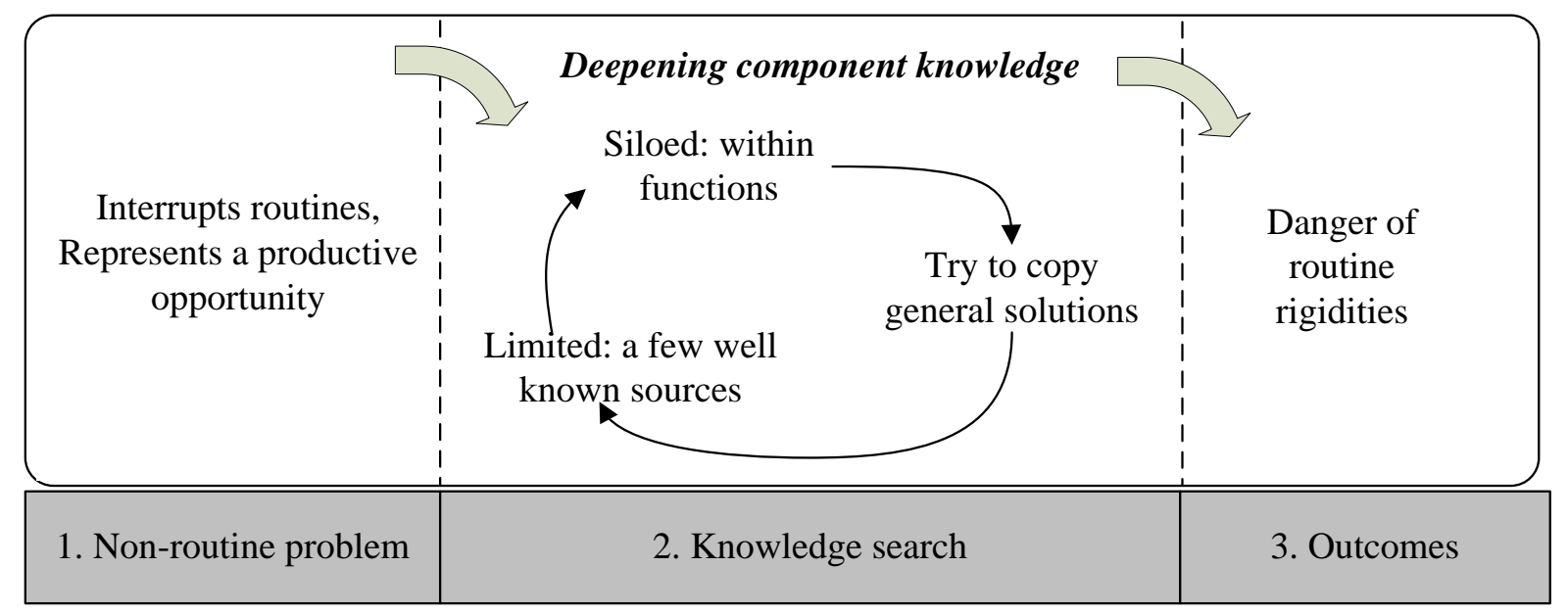

Figure 2: Middle managers'knowledge searchroutinesin Gamma

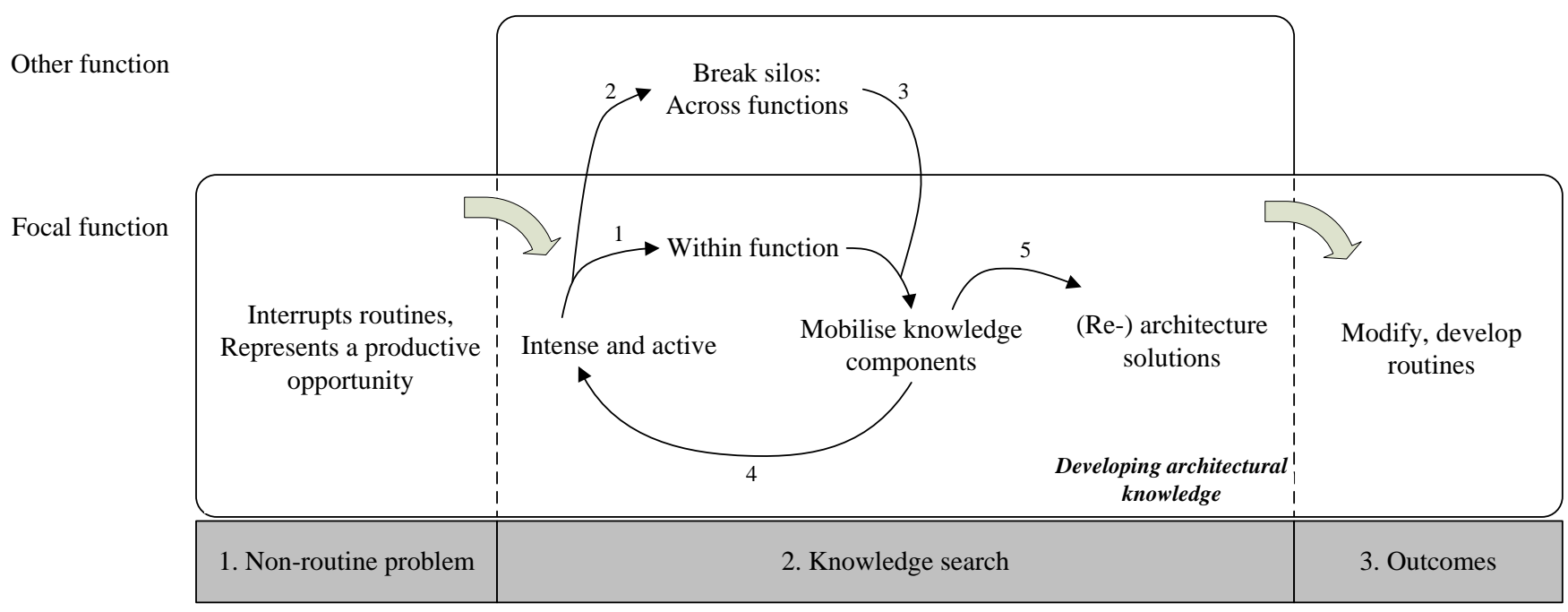


Table 1: Overview of middle managers' knowledge search routines

\begin{tabular}{|c|c|c|c|c|c|}
\hline \multirow[t]{2}{*}{ Case } & \multirow{2}{*}{$\begin{array}{l}\text { Non-routine } \\
\text { problem }\end{array}$} & \multicolumn{3}{|c|}{ Knowledge search routine } & \multirow[b]{2}{*}{$\begin{array}{l}\text { Architectured } \\
\text { solution }\end{array}$} \\
\hline & & $\begin{array}{l}\text { Intensity } \\
\text { (no. of units } \\
\text { approached) }\end{array}$ & Diversity in knowledge components & Functional domain & \\
\hline 1 & $\begin{array}{l}\text { Develop internal } \\
\text { processes }\end{array}$ & 5 & $\begin{array}{l}\text { - Practice: processes embedded in tools (1) } \\
\text { - Practice: understanding of practice (1) } \\
\text { - Specialist expertise, competence (3) }\end{array}$ & $\begin{array}{l}\text {-Within function (3) } \\
\text { - Outside function (2) }\end{array}$ & Routine generation \\
\hline 2 & $\begin{array}{l}\text { Develop internal } \\
\text { processes }\end{array}$ & 3 & $\begin{array}{l}\text { - Practice: processes embedded in } \\
\text { document (1) } \\
\text { - Specialist expertise, competence (1) } \\
\text { - Experience, advice from peer }(1)\end{array}$ & $\begin{array}{l}\text {-Within function (1) } \\
\text { - Outside function (2) }\end{array}$ & Routine modification \\
\hline 3 & $\begin{array}{l}\text { Develop sales } \\
\text { business }\end{array}$ & 2 & - Experience, advice from peers (2) & -Within function (2) & Routine modification \\
\hline 4 & $\begin{array}{l}\text { Develop internal } \\
\text { processes }\end{array}$ & 2 & - Specialist expertise, competence (2) & • Outside function (2) & Routine modification \\
\hline 5 & $\begin{array}{l}\text { Develop sales } \\
\text { business }\end{array}$ & 3 & $\begin{array}{l}\text { - Practice: processes embedded in tools (1) } \\
\text { - Specialist expertise, competence (2) }\end{array}$ & $\begin{array}{l}\text {-Within function (1) } \\
\text { - Outside function (2) }\end{array}$ & Routine modification \\
\hline 6 & $\begin{array}{l}\text { Develop sales } \\
\text { business }\end{array}$ & 3 & $\begin{array}{l}\text { - Practice: processes embedded in tools(1) } \\
\text { - Practice: understanding of practice (1) } \\
\text { - Specialist expertise, competence (1) }\end{array}$ & $\begin{array}{l}\text { - Within function (1) } \\
\text { • Outside function (2) }\end{array}$ & Routine modification \\
\hline 7 & $\begin{array}{l}\text { Optimise and } \\
\text { automate } \\
\text { operations }\end{array}$ & 2 & $\begin{array}{l}\text { - Practice: processes embedded in tools(1) } \\
\text { - Specialist expertise, competence(1) }\end{array}$ & $\begin{array}{l}\bullet \text { Within function (1) } \\
\text { • Outside function (1) }\end{array}$ & Routine modification \\
\hline 8 & $\begin{array}{l}\text { Develop internal } \\
\text { processes }\end{array}$ & 2 & $\begin{array}{l}\text { - Specialist expertise, competence (1) } \\
\text { - Experience, advice from peers (1) }\end{array}$ & $\begin{array}{l}\bullet \text { Within function (1) } \\
\text { • Outside function (1) }\end{array}$ & Routine modification \\
\hline 9 & $\begin{array}{l}\text { Optimise and } \\
\text { automate } \\
\text { operations }\end{array}$ & 6 & $\begin{array}{l}\text { - Specialist expertise, competence (4) } \\
\text { - Experience, advice from peers (2) }\end{array}$ & $\begin{array}{l}\text {-Within function (2) } \\
\text { • Outside function (4) }\end{array}$ & Routine generation \\
\hline 10 & $\begin{array}{l}\text { Develop internal } \\
\text { processes }\end{array}$ & 2 & $\begin{array}{l}\text { - Practice: processes embedded in tools (1) } \\
\text { - Practice: understanding of practice (1) }\end{array}$ & -Within function (2) & Routine modification \\
\hline 11 & $\begin{array}{l}\text { Optimise and } \\
\text { automate } \\
\text { operations }\end{array}$ & 4 & $\begin{array}{l}\text { - Practice: processes embedded in tools (1) } \\
\text { - Practice: understanding of practice (1) } \\
\text { - Specialist expertise, competence (2) }\end{array}$ & $\begin{array}{l}\text {-Within function (2) } \\
\text { • Outside function (2) }\end{array}$ & Routine generation \\
\hline 12 & $\begin{array}{l}\text { Develop sales } \\
\text { business }\end{array}$ & 5 & $\begin{array}{l}\text { - Practice: understanding of practice (1) } \\
\text { - Specialist expertise, competence (2) } \\
\text { - Experience, advice from peers (2) }\end{array}$ & $\begin{array}{l}\text {-Within function (3) } \\
\text { • Outside function (2) }\end{array}$ & Routine generation \\
\hline 13 & $\begin{array}{l}\text { Develop internal } \\
\text { processes }\end{array}$ & 2 & $\begin{array}{l}\text { - Practice: processes embedded in tools (1) } \\
\text { - Practice: understanding of practice (1) }\end{array}$ & -Within function (2) & Routine modification \\
\hline 14 & $\begin{array}{l}\text { Optimise and } \\
\text { automate } \\
\text { operations }\end{array}$ & 6 & $\begin{array}{l}\text { - Practice: processes embedded in tools (1) } \\
\text { - Practice: understanding of practice (2) } \\
\text { - Specialist expertise, competence }(2) \\
\text { - Experience, advice from peers }(1)\end{array}$ & $\begin{array}{l}\text { - Within function (1) } \\
\text { • Outside function (5) }\end{array}$ & Routine generation \\
\hline
\end{tabular}




\section{Table 2: Flexible organizational design elements}

\begin{tabular}{ll}
\hline Elements & Relevant quote(s) from Gamma managers \\
\hline Flexible organizational & $\begin{array}{l}\text { "The way I had problems, I guess, describing to you my title, it's very } \\
\text { structure } \\
\text { similar within Gamma. So not necessarily what might be the norm in } \\
\text { another company, does not need to be the norm within Gamma." } \\
\text { (Manager 5) }\end{array}$ \\
$\begin{array}{l}\text { Flat, unpronounced } \\
\text { hierarchy }\end{array}$ & "It's all about lateral or flat management." (Director) \\
Empowerment and & "So what we do is present that analysis to [the Director] and get his \\
inclusive decision & feedback. And he gave feedback: That seems to be working - let's invest \\
making & further, let's roll it out to new countries." (Manager 8) \\
& "He [Director] would be checking that the right steps are in place." \\
& (Manager 6) \\
Flexible time allocation & "I would say that even though we are very busy, we always have time to \\
& think about the things and come up at least with potential solutions to \\
& improve it." (Manager 7) \\
& "That's the biggest challenge to choose what to do." (Manager 4)
\end{tabular}


Table 3: Implications of flexible organizational design elements

\begin{tabular}{|c|c|c|}
\hline \multirow[t]{2}{*}{ Elements } & \multicolumn{2}{|l|}{ Implications for managers' knowledge search routines } \\
\hline & Benefits & $\begin{array}{l}\text { Pitfalls (challenging } \\
\text { elements) }\end{array}$ \\
\hline $\begin{array}{l}\text { Flexible } \\
\text { organizational } \\
\text { structure }\end{array}$ & $\begin{array}{l}\text { - Minimises bureaucracy and unnecessary } \\
\text { procedures when developing solutions. } \\
\text { - More likely to come across dissimilar, diverse } \\
\text { knowledge components from different functions } \\
\text { for (re-) architecturing. }\end{array}$ & $\begin{array}{l}\text { - Organization appears chaotic } \\
\text { and unstructured, even like a } \\
\text { mess. } \\
\text { - Can be difficult to locate } \\
\text { knowledge components } \\
\text { because managers do not } \\
\text { know who is responsible for } \\
\text { what and who knows what. } \\
\text { - Repeated search attempts } \\
\text { may be necessary until } \\
\text { knowledge component is } \\
\text { located. }\end{array}$ \\
\hline $\begin{array}{l}\text { Flat, } \\
\text { unpronounced } \\
\text { hierarchy }\end{array}$ & $\begin{array}{l}\text { - Easy for managers to contact key decision makers } \\
\text { (senior and top managers) for investment, but } \\
\text { importantly also for their expertise to prevent } \\
\text { narrow focus. } \\
\text { - Small management group is familiar to each other. } \\
\text { Facilitates bringing together the right people to } \\
\text { discuss issues and potential solutions. Encourages } \\
\text { deep searching within function. }\end{array}$ & \\
\hline $\begin{array}{l}\text { Empowerment } \\
\text { and inclusive } \\
\text { decision } \\
\text { making }\end{array}$ & $\begin{array}{l}\text { - Managers take the ownership over solution } \\
\text { advancement and pilot new practise and processes } \\
\text { in their own unit. } \\
\text { - Managers do not act in isolation and consult key } \\
\text { experts from within and across functions to } \\
\text { mobilise knowledge components. }\end{array}$ & \\
\hline $\begin{array}{l}\text { Flexible time } \\
\text { allocation }\end{array}$ & $\begin{array}{l}\text { - Managers can allocate time for the search for } \\
\text { knowledge and solution development. Increases } \\
\text { the intensity and scope of search. Prevents local } \\
\text { search and repeated use of the same contacts. } \\
\text { - Managers can strive for developing } \\
\text { comprehensive solution rather than rush or cover } \\
\text { up extent of non-routine problem. }\end{array}$ & \\
\hline & $\begin{array}{l}\text { Overall: } \\
\text { - Intense and active search for knowledge. } \\
\text { - Breaking silos: within and across functional search. } \\
\text { - Mobilize diverse knowledge components. }\end{array}$ & \\
\hline
\end{tabular}


Table 4: Deformalised, loose strategy for managing knowledge

\begin{tabular}{ll}
\hline Elements & Relevant quote(s) from Gamma managers \\
\hline De-emphasis of & "We don't have a process or mechanism." (Manager 7) \\
knowledge repositories & "And then, when it was established, yes, it had been looked at long time \\
& ago, but a lot of those people have left since then. That knowledge \\
& would not have stayed within Gamma since then." (Manager 5) \\
Interaction opportunities & "It is very natural, it is very informal. We also try sometimes to have \\
and informality & regular meetings with people to really understand what is happening \\
& etcetera. But it is much more informal. ... there is no procedure. No, \\
& no, no. It's an area where we all do it naturally and also understand: \\
& How do we want to do it?" (Manager 7) \\
& "I think they are very open. I think it's a Gammaly thing that people try \\
& to listen and try to be open to others." (Manager 5) \\
"In this respect I really like the people I work with; everybody is very \\
Openner to help and you would get an honest opinion." (Manager 2)
\end{tabular}


Table 5:Implications of deformalised, loose strategy for managing knowledge

\begin{tabular}{|c|c|c|}
\hline Elements & \multicolumn{2}{|c|}{ Implications for middle managers' knowledge search routines } \\
\hline & Benefits & Pitfalls (challenging elements) \\
\hline $\begin{array}{l}\text { De-emphasis of } \\
\text { knowledge } \\
\text { repositories }\end{array}$ & $\begin{array}{l}\text { - Forces managers to engage in } \\
\text { interpersonal search. } \\
\text { - Chance for renewed architecturing and } \\
\text { design of superior solution if existing } \\
\text { knowledge is not located. }\end{array}$ & $\begin{array}{l}\text { - More difficult to know who to talk } \\
\text { to when seeking knowledge. } \\
\text { Repeated search attempts may be } \\
\text { necessary until knowledge } \\
\text { component is located. } \\
\text { - 'Duplication' of solutions if } \\
\text { existing knowledge is (re- } \\
\text { )architectured. }\end{array}$ \\
\hline $\begin{array}{l}\text { Interaction } \\
\text { opportunities and } \\
\text { informality }\end{array}$ & \multicolumn{2}{|l|}{$\begin{array}{l}\text { - Creates a small company feel where } \\
\text { managers have large social network of } \\
\text { employees, management peers and } \\
\text { seniors that can become channels for } \\
\text { knowledge search. } \\
\text { - Interaction with colleagues from } \\
\text { different functions which can add } \\
\text { diverse knowledge components. } \\
\text { - Frequent informal exchanges as chance } \\
\text { to locate useful knowledge components }\end{array}$} \\
\hline \multirow[t]{2}{*}{ Openness } & $\begin{array}{l}\text { - Colleagues from any unit and } \\
\text { department are willing to help and to } \\
\text { share their 'best' practices and } \\
\text { expertise. } \\
\text { - Managers prefer to collaborate for } \\
\text { solution finding and tap into different } \\
\text { knowledge pools. Avoids rigidities and } \\
\text { stimulates search for new, previously } \\
\text { unknown knowledge components. }\end{array}$ & \\
\hline & \multicolumn{2}{|c|}{$\begin{array}{l}\text { Overall: } \\
\text { - Breaking silos: within and across functional search. } \\
\text { - Mobilize diverse knowledge components. } \\
\text { - (Re-)architecture knowledge components into novel solutions. }\end{array}$} \\
\hline
\end{tabular}


Table 6: Summary of implications for management practice

Implications for Management Practice

- Trust middle managers' ability to modify and craft new routines

- Encourage knowledge search rather than promote knowledge management tools and procedures

- Utilise advantage of modularity when architecturing solutions

- Value individual discovery and re-architecturing rather than overly rigid replication

- Develop knowledge architecture competences 
Table A1: Category building for Gamma's organizational context

\begin{tabular}{|c|c|c|}
\hline First-order (informant) concepts & Second-order themes & Aggregate category \\
\hline $\begin{array}{l}\text { Unstructured / disorganised / } \\
\quad \text { chaotic / mess } \\
\text { Minimise bureaucracy } \\
\text { Some / light structures } \\
\text { Difficult to know who does } \\
\text { what }\end{array}$ & $\begin{array}{l}\text { Flexible organizational } \\
\text { structure }\end{array}$ & \\
\hline $\begin{array}{l}\text { Flat management } \\
\text { Not many layers } \\
\text { Minimise hierarchy } \\
\text { Feedback from / run it by } \\
\quad \text { seniors }\end{array}$ & $\begin{array}{l}\text { Flat, unpronounced } \\
\text { hierarchy }\end{array}$ & $\begin{array}{l}\text { Flexible } \\
\begin{array}{l}\text { organizational } \\
\text { design }\end{array}\end{array}$ \\
\hline $\begin{array}{l}\text { Lead solution finding } \\
\text { Left to me / Leave it to } \\
\text { employees }\end{array}$ & $\begin{array}{l}\text { Empowerment and } \\
\text { inclusive decision } \\
\text { making }\end{array}$ & \\
\hline $\begin{array}{l}\text { Time to work on projects } \\
\text { Busy with everyday work } \\
\text { Have to prioritise }\end{array}$ & Flexible time allocation & \\
\hline
\end{tabular}

No process / mechanism

No central repository of knowledge

Failed attempts to create central area for projects / initiatives

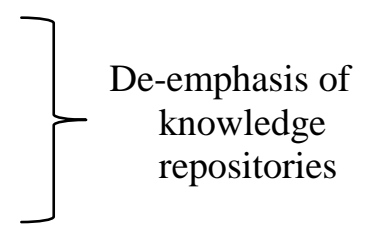

Frequent interactions and exchange

Natural and informal

Know people / have contacts

Small-company feel

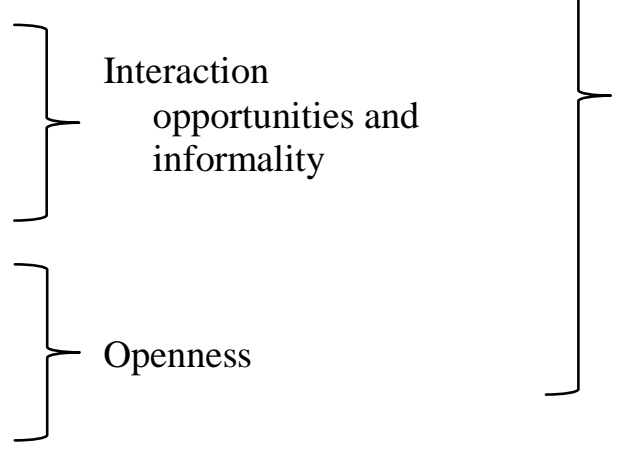

Loose, informal

strategy for

managing

knowledge

Share

Collaborate

Very open

Eager to help 